life, as well as discussing their enemies and their relations with man. The author is inclined to overstress that bears are not generally the dangerously aggressive villains as popularly portrayed; personal experience of the sloth bear in India indicates this is not a matter for complacency. Leslie Brown, who has for decades indulged in intimate study of the fierce, magnificent eagles, mainly in Kenya and Scotland, provides entertaining, informative reading about these 'powerful, rapacious, diurnal birds of prey'. African eagles figure extensively in the illustrations. Gorillas constitutes an intriguing analysis of where these huge apes are found, how they live and grow up, and their attitude towards man. The alleged ferocity of the gorilla is properly debunked and its natural benign temperament, for which the reviewer can vouch from first hand experience, emphasised: enthralling, lucid and informative.

C. R. S. PITMAN

Aldabra Alone, by Tony Beamish. Allen \& Unwin, 50 s.

This is a narrative of the author's visit, early in 1967 , to a truly unique atoll-many of its animals and plants are found on Aldabra alone; a description of the island and its wildlife gradually unfolds. With a few companions, Tony Beamish was able to make a circuit of the island, partly on land and in places with difficulty over honeycombed and spiky coral, partly by boat on the central lagoon when the tide permitted, and partly by sea outside the fringing reef. A dated itinerary would have usefully supplemented the sketch-map; and an index to the scattered mentions of species would have helped. The Indian Ocean giant tortoise has here its last natural home, but exists in prodigious numbers. The special birds, notably unafraid of man, include the flightless white-throated rail, the Aldabra brush-warbler and the Aldabra drongo; and there are large colonies of some of the pantropical seabirds. Interwoven is another narrative, that of the battle that was being successfully waged thousands of miles away to save this unspoilt paradise and scientific treasure-house from being wrecked for ever by myopic military vandals.

To those, like the reviewer, who have no more than set foot on the island, and briefly sailed its interior lagoon (and by mischance the surrounding sea!) in a rubber dinghy, this account fills many gaps. To those who have not even had that experience, it must surely conjure up a vivid picture of a strange place, full of bright beauty and fascinating interest. The fine colour plates, from photographs by the author and others, greatly assist. Sir Julian Huxley contributes a foreword, and Dr W. R. P. Bourne an appendix on the birds.

LANDSBOROUGH THOMSON

The Wild Mammals of Malaya, by Lord Medway. Oxford University Press, £6 5s.

Mammals in Hawaii, by P. Quentin Tomich. Bishop Museum Press, Honolulu, $\$ 5.00$.

One could hardly find two more dissimilar mammalian faunas than those of Malaya and Hawaii - the former with 200 species of land mammals, all but one or two indigenous, the latter with probably only one land mammal that might have reached the islands by its own efforts, an American bat.

Lord Medway's volume is unique and valuable on several counts. It provides a concise account of distribution, identification characters, habits and life-history of all species, large and small, in the Malayan 
peninsula, and illustrates $\mathrm{I} I 4$ of them in colour; it is the first such account not only for Malaya, but anywhere in the Oriental Region, with the possible exception of the same author's Mammals of Borneo (which lacks colour plates). Since many of the species involved extend far beyond the boundaries of Malaya, from India and southern China to Java and Borneo, its field of usefulness is extensive. An introductory chapter clearly describes the protection legislation, but few clues are provided about the prospects for the few seriously threatened species such as the Sumatran rhino and the tapir. One species, the Javan rhino, is already extinct on the mainland. The rain-forest habitat is reflected in an astonishing diversity of bats, with $8 \mathrm{r}$ species already recorded and additions being made annually, and of squirrels, with 25 species. Considering the small size of the country, comparable to England, this is an astonishing fauna, dangerously dependent upon the survival of forest.

In Hawaii the sole and endemic bat has been joined by nineteen other terrestrial mammals ranging from feral domestic stock (e.g. about 2000 head of feral cattle) to uninvited rats and deliberately introduced mongooses and game ungulates. Mouflon, pronghorn, mule deer and axis deer have all been recently introduced for hunting, and apparently further candidates are being considered. Protesting voices are numerous but ineffective. In an island where the ancient inhabitants used miniature bows and arrows for sport shooting of the Polynesian rat anything seems possible!

Dr Tomich has produced a detailed, almost pedantic, account of the successful and unsuccessful introductions of terrestrial mammals; he has briefer accounts of the marine species, one of which, the endemic monk seal, provides a happier story. After being close to extinction at the beginning of the century, the numbers today are over a thousand.

G. B. CORBET

\section{A Field Guide to the Larger Mammals of Africa, by Jean Dorst and} Pierre Dandelot. Collins, $50 \mathrm{~s}$.

The latest of the well known Collins' Field Guide series fulfils its purpose admirably. Though dealing principally with the ungulates, Carnivora and primates, it also considers the pangolins, aardvark, manatee and several small mammals such as squirrels and elephant shrews-in fact all those likely to be encountered in Africa by anyone other than a specialist. Identification, habitat, habits, similar species, and where necessary intraspecific variation are discussed; English and scientific names are supplemented by names in French, German, Afrikaans and Swahili.

Despite the authors' disclaimer that the book is not concerned with systematics, they have tried to keep up with current trends in classification, and draw attention to cases where two forms regarded by other authors as conspecific have been treated by them as separate species, which is most useful for the general reader. The range maps, though small, come out very well, and within their declared limitation give a good idea of distribution. It is particularly gratifying to see the break in distribution between south-western and eastern Africa shown for such species as the spring hare, bat-eared fox and the oryxes, Oryx gazella and O. beisa, which the authors regard as separate species, rather than the continuous range so often, erroneously, indicated. On page IO2 the authors state that young wild dogs follow their mother after one week. This is surely wrong-they would not have opened their eyes; three months or so is more likely.

The colour illustrations, comprising 44 plates depicting virtually every 